\title{
The Construction of the Canonical History of Financial Economics
}

\author{
Franck Jovanovic
}

Only recently have economists turned their attention to the history of financial economics; indeed, the earliest studies date from just the middle of the last decade. By and large, the evolution of financial economics has been presented as one of linear progress. However, Jovanovic 2002 explains that the development of the subdiscipline was anything but linear, as one would see by examining the actual historical record. Moreover, Jovanovic 2003b shows that construing the story of financial economics as one of linear progress is inconsistent with much historical data ${ }^{1}$-data that renders the linear-progress story false. This article deals with that problem. It has two major goals.

The first is to explain the origin of the linear-progress story with respect to the purported history of financial economics that economists have typically told. This article suggests that the mismatch between the typical presentation and the historical data has arisen because most commentators have drawn on the canonical history of financial economics-a history

\footnotetext{
Correspondence may be addressed to Franck Jovanovic, TELUQ-UQAM, 100, Sherbrooke West, Montréal, QC, H2X 3P2, Canada; e-mail: jovanovic.franck@teluq.uqam.ca. I wish to thank the two referees, participants at the H2S seminar and the HES 2004 conference, Philippe Le Gall, Robert Leonard, and Sean Dwyer.

1. In accordance with the historical approach, I distinguish historical data from historical facts. Historical data are the primary pieces of evidence, or of the historical record, which come from archeology, testimonies, and archives. Historians use historical data to construct historical facts.
}

History of Political Economy 40:2 DOI 10.1215/00182702-2008-001

Copyright 2008 by Duke University Press 
that draws on too narrow a range of sources. This article highlights that point by analyzing how and why the canonical history was elaborated. A canonical history can be defined as a history created from a canon of texts ${ }^{2}$ - that is, from a selection of texts-without recourse to other historical data. In other words, such a history orders selected theoretical texts chronologically and then creates between the texts ex-post links that explain the chronology. However, those links are neither historical assumptions nor historical results; they are invented stories of the past. This article shows that the canonical history of financial economics was created during the 1960s to support theoretical viewpoints, theoretical viewpoints that led the mainstream community of scientists to recognize financial economics as a science.

The second goal is to analyze the introduction of financial economics ${ }^{3}$ into economics during the 1960s, and therefore its acceptance as a scientific subdiscipline. This point has never been studied: the canonical history of financial economics and the traditional presentation that followed do not examine this introduction, nor refer to it at all. Indeed, they suppose that financial economics had existed since the first theoretical or empirical works were published. Therefore, many questions remain unanswered. This article focuses on the 1960s, a crucial decade in the construction of the subdiscipline: although works in financial economics had existed since the mid-nineteenth century, the subdiscipline was only brought into science during the 1960s. The concept of a scientific field is useful for analyzing the creation of that subdiscipline. According to Bourdieu (2004, 33), who introduced the concept, a scientific field is "a structured field of forces, and also a field of struggles to conserve or transform this field of forces." Through their relationships, individuals create the very space (i.e., the structure of the field) that determines them, thanks to the forces that are exerted on scientific production and scientific practices. Moreover, each scientific discipline or subdiscipline imposes its own rules, behaviors, methods, etc., to distinguish itself from other scientific disciplines and from approaches recognized as nonscientific. Relying on Gingras, Bourdieu $(2004,50)$ identifies two steps within the development of a scientific field: "First, the emergence of a research practice, in other words,

2. A canon is a privileged set of texts whose interpretation and reinterpretation define the background of a discipline.

3. It seems important to differentiate financial economics, which is identified here as the subdiscipline, from mathematical finance, which can be identified as mathematics applied to finance, and financial econometrics, which can be considered as econometrics applied to financial data. 
agents whose practice is based more on research than on teaching, and the institutionalization of research in universities through the creation of conditions conducive to the production of knowledge and the long-term reproduction of the group; and, secondly, the constitution of a group recognized as socially distinct and a social identity, either disciplinary, through the creation of scientific associations, or professional, with the creation of a corporation - the scientists provide themselves with official representatives to give them social visibility and defend their interest."

The concept of a scientific field helps us to better understand financial economics and its creation. When creating a new scientific subdiscipline, the creators must accept that the new subfield will have to fight against the structure of the existing larger field as they struggle to promote and establish their new results, concepts, hypotheses, theories, etc. In other words, when it is created, the new scientific subdiscipline cannot be independent from the existing structure: it must be created with and against the existing field of forces, results, etc. This article will focus on one particular point that shows the integration of financial economics into science: the theoretical explanation. Financial economics became a scientific subdiscipline as a consequence of the theoretical explanations given to empirical and statistical results accumulated during several decades. Indeed, following Bourdieu $(1975,96)$, "we have to distinguish the [scientist] who has discovered the unknown phenomenon from the one who made it a new scientific fact integrating it in a theoretical construction" of a scientific discipline, which accordingly places it within science. For instance, during the 1960s, the random character of stock market prices became a scientific fact about one hundred years after its discovery by Jules Regnault in $1863 .{ }^{4}$ The same is true for the portfolio selection model, developed by Markowitz (1952) and Roy (1952), which also became a scientific fact during the 1960s by receiving a theoretical explanation. More generally, it was consistently during the 1960s that many discoveries by financial economists became scientific facts. It was also during that decade that a canonical history of the subdiscipline emerged to support the new theoretical explanations.

The integration of financial economics into science was made possible by the synthesis of results. These results belong to three analytical components that were developed successively: financial econometrics, the modern probability theory, and economic equilibrium. Efficient market theory,

4. Jovanovic (2006) and Jovanovic and Le Gall (2001) analyze Regnault's work. A biography of Regnault is available in Jovanovic 2006. 
CAPM, and Modigliani-Miller theorems played a key role in this synthesis, and therefore in the rise of financial economics. They established links between, on the one hand, empirical and mathematical results in finance, and on the other hand, economic equilibrium. These links led to the creation of theoretical explanations for empirical results, explanations that were the last step in the categorization of financial economics as a scientific subdiscipline. This article focuses on efficient market theory. However, results presented here can be generalized for all subjects analyzed by financial economics for CAPM or Modigliani and Miller's article (Jovanovic 2007).

Part 1 examines the incorporation of this new subdiscipline into science during the $1960 \mathrm{~s}$, in particular its position toward the existing approach and economics. This first part shows that the organization of financial economics as a scientific subdiscipline was only made during the 1960 s.

Part 2 analyzes the internal organization of financial economics during the 1960s to show how the subdiscipline was structured as a scientific field. It explains that two theoretical viewpoints existed and that they led to the creation of two canonical histories to support them.

\section{The Creation of Financial Economics: The Integration of Theoretical Hypotheses and Empirical Results into the Scientific Field}

Before the 1960s, works in financial economics were very marginal in the scientific field. Milton Friedman's reaction against Harry Markowitz's $\mathrm{PhD}$ thesis gives a good illustration. The thesis, defended in 1952, deals with the theory of portfolio selection. It is one of the first Anglo-American works in what it is now called financial economics that was not exclusively empirical. In the defense, Friedman declared: "Harry, I don't see anything wrong with the math here, but I have a problem. This isn't a dissertation in economics, and we can't give you a Ph.D. in economics for a dissertation that's not economics. It's not math, it's not economics, it's not even business administration" (Bernstein 1992, 60).

While Friedman's reaction could be considered inappropriate or excessive, given the importance of Markowitz's work today, it is understandable in the light of Markowitz's contribution in his 1952 article. That article used mathematical properties of random variables to show that the diversification of shares from a portfolio could reduce the variability of returns: the expected value of a weighted sum is the weighted sum of the expected 
values, while the variance of a weighted sum is not the weighted sum of the variances. Markowitz did not give any theoretical demonstration of his mathematical result; he merely provided a financial interpretation of some mathematical properties. ${ }^{5}$ Therefore, Friedman's reaction is a good signal about the situation of financial economics before the 1960s, and more specifically before Modigliani and Miller's contribution in 1958: the few existing works did not constitute either an academic or a scientific discipline yet; there were applied mathematics and empirical investigations, but these were isolated contributions, and they lacked a solid theoretical underpinning. This situation changed with the creation and the organization of a new community during the 1960s.

This first part shows that financial economics became a science during the 1960s. It analyzes two developments: first, the construction of a new scientific community, which had two main groups of researchers; second, the integration of this community into science, thanks to economics.

\subsection{The Rise of a New Scientific Community}

Three features point out the rise of a new scientific community: first, the creation of groups of researchers; second, a common training; and third, the affirmation of a specific method.

The creation of a community with two main groups of researchers. At the beginning of the 1960s, a new generation of economists started their graduate studies and contributed to the creation of financial economics. ${ }^{6}$ Studies about financial markets or corporate finance were not new; what was new was the manner in which they were studied. One major feature was the access to new mathematical tools borrowed from modern probability theory. Since the 1950s, modern probability theory was increasingly used to study financial markets and corporate finance. At the beginning, economists and other researchers exploited the properties of random variables. Then they used stochastic processes, which probability theory analyzed. Before the 1960s, hardly any economist and financier used these processes, because they were not well understood and they were not widely disseminated. Effectively, the modern probability theory, which mainly

5. Obviously, this situation completely changed with the publication of Markowitz's book in 1959, which gives a theoretical explanation to his model.

6. Among them were John Bauer, Eugene Fama, Benjamin King, Arnold Larson, Sydney Levine, Jacob Michaelson, Arnold Moore, William Sharpe, William Steiger, and Alan Wright. 
comes from Kolmogorov's work, received genuinely wide acceptance in the 1950s by the new generation of mathematicians (see Mazliak 2003 and Chaumont et al. 2004). Even during the 1960s, few economists or financiers used stochastic processes. For instance, Samuelson (1965a, 1965b), who was the first with Mandelbrot (1966) to substitute the martingale model ${ }^{7}$ for the random walk model/Brownian motion to represent stock price variations, needed the help of a mathematician to make his mathematical demonstration (Samuelson 1965b).

With the use of stochastic processes, in the 1960s the mathematical treatment of the random character of stock market variations took on a large importance. Most of the academics who innovatively studied financial markets with modern probability theory during the 1960 s and the 1970s were at the University of Chicago or MIT.

At the University of Chicago, research on the random character of stock market prices began at the Graduate School of Business, where Harry Roberts worked with James Lorie and Lawrence Fisher. In 1960, the latter two professors started an ambitious four-year program of research on security prices. ${ }^{8}$ They created the Center for Research in Security Prices (CRSP), which had an important group of PhD students such as Eugene Fama, Benjamin King, and Arnold Moore. Merton Miller joined them one year later, in $1961 .^{9}$

At the same time, MIT opened a new area of research on the random character of stock market prices with Sidney Alexander, Paul Cootner, Dick Eckaus, Hendrik Houthakker (visiting professor), Ed Kuhn, Paul Samuelson, and several students, including Walter Barney, John Bauer, Sidney Levine, William Steiger, and Richard Kruizenga. During the 1960s, Cootner supervised more than twenty theses in financial economics and became an essential figure in the development of the subdiscipline at MIT.

The training of the new entrants: the creation of scientific journals and seminars and the publication of textbooks. The creation of a new sci-

7. A sequence of random variables $P_{t}$ adapted to $\left(\Phi_{n} ; 0 \leq n \leq N\right)$ is called a martingale if $\mathrm{E}\left(P_{t+1} / \ddot{\mathrm{O}}_{0}, \ddot{\mathrm{O}}_{1}, \ldots, \ddot{\mathrm{O}}_{t}\right)=P_{t}$. This means that the best estimation of the security's price at time $t+1, P_{t+1}$ with the available information at time $t, \Phi_{t}$, that we can come up with at time $t$ is the security's price at time $t, P_{t}$. Thus the expected profit, $y$, between two periods, considering the available information at time $t, \Phi_{t}$, is zero $\mathrm{E}\left(y_{t+1} / \ddot{\mathrm{O}}_{t}\right)=0$.

8. Lorie was recruited in 1951 at Chicago specifically to revitalize the Graduate School of Business.

9. Fischer Black, whose successor was Myron Scholes, also managed the center. Both participated in the elaboration of the option pricing model, which was published in 1973 and was mainly developed by researchers from the CRSP and MIT. See Mehrling 2005, chap. 5. 
entific community requires that its new members share common tools, references, and problems. This was precisely the role of textbooks, seminars, and scientific journals. Those in financial economics were developed from the beginning of the 1960s with the arrival of this new generation of students. Concerning periodicals, the two journals that had published articles in finance, the Journal of Finance and the Journal of Business, changed their editorial policy during the 1960s. Both started publishing articles based on modern probability theory and on modeling (see Bernstein 1992, 41-44, 129). Those two reviews published several special issues to reinforce the new orientation and results. In 1966, the Journal of Business published a special issue on "recent quantitative and formal research on the stock market." In addition to those two journals, other scientific journals specializing in financial economics were created, such as the Journal of Financial and Quantitative Analysis in 1965. In 1968, the journal just mentioned published a special issue about the application of the random walk model to stock prices.

It was also during the 1960s that textbooks and collections of articles started to appear..$^{10}$ These publications also helped to define and stabilize a culture shared by the members of the new community. Given that collections of articles are published before textbooks, interval between the moment when the former were published and the moment when the textbooks were published gives an indication about the evolution of the discipline. Indeed, the diversification of the subjects analyzed and the publication of textbooks are good indicators with which to identify the period when a new scientific subdiscipline is finally accepted. During the 1960s, following the publication of Markowitz's book in 1959, the publications of collected articles focused on portfolio selection; it was only at the end of the 1960s that textbooks on the subject were published. During the second part of the decade, there was a diversification of subjects, which started to structure the discipline. In addition to portfolio selection, journal articles dealt with the nature of stock price movements, the investment returns, market efficiency, and the CAPM or capital asset pricing model. However, textbooks on these subjects only first appeared during the 1970s.

In 1964, the first anthology of articles analyzing random stock price movements was published: The Random Character of Stock Market Prices, edited by Paul Cootner. It has an important place in the history

10. For instance, Cootner (1964), Fredrikson (1965), Wu and Zakon (1965), Fredrikson (1971), and Lorie and Brealey (1972) published collections of articles, while Moore (1968), Mao (1969), Jean (1970), and Fama and Miller (1972) published textbooks. 
of financial economics for three reasons. First, it contributed enormously to the spread of the random walk model and its interpretation. Second, it sketched a research program for the future that was largely followed. Third, the book provided the first presentation of historical data relative to financial economics.

The differentiation from existing approaches. The third feature deals with the definition of a new field of investigation. The new scholars who started to develop financial economics adopted a new strategy to differentiate the new domain of research from previous approaches and to justify the usefulness of their new approach. Scholars mentioned above and who developed financial economics provide a good illustration of this. Young scholars opened several debates comparing the qualities of their new approach, mainly based on mathematical models and tools-in particular the random walk model-and previous approaches that studied stock price changes, in particular chartism and business cycles, such as those defended at the NBER. The debates generally took place in specialized journals and newspapers, such as Business Week and the Financial Analysts Journal, ${ }^{11}$ in which scholars popularized their results. To justify the new approach, those in the avant-garde of financial economics presented their arguments in Manichean terms, underlining what is scientific and what is not, what comes from scholars and what comes from nonscholars. For instance, Cootner $(1964,1-2)$ introduced his book by saying that

these academic studies have proven to be more skeptical about the folklore of the market place than those of the professional practitioners. To several of the authors represented in this volume the "patterns" described by some market analysis are mere superstitions. . . . it is hard to find a practitioner, no matter how sophisticated, who does not believe that by looking at the past history of prices one can learn something about their prospective behavior, while it is almost as difficult to find an academician who believes that such a backward look is of any substantial value. The essays in this book are exclusively of the academic type.

As did other defenders of the random walk model and the new ideas, Fama (1965b, 59) and Archer (1968, 231-32) presented their results as a "challenge" to professionals - chartists, brokers, financial analysts-in short, all

11. See for example the debate between Levy $(1967,1968)$ and Jensen (1967). See also Granger 1970, Hoffland 1967, Shelton 1967, Van Horne and Parker 1968, and Wallich 1968. 
people who work in financial markets and who are distinguished here from scholars. The professionals in turn had to justify the usefulness of their practices. Finally, Hoffland $(1967,85)$ provided a good summary of the situation:

Folklore is a body of knowledge incorporating the superstitions, beliefs and practices of the unsophisticated portion of a society. ... Folklore is distinguished from scientific knowledge by its lack of rigor. ... The Dow theory is often used as an example of a crudely formulated stock market "theory."

As we see, the most important argument was the scientific claim: the new financial economists argued that their approach was based on scientific criteria, while chartism was based on folklore and had no scientific foundation. Financial economics was supposed support previous folkloric practices, and the random walk model was presented as the uniquely available scientific analysis of the character of stock price changes. The vocabulary used was intentionally clear-cut to convince the reader: "scientific," "folklore," "challenge." In addition, academics chose to call the new discipline modern financial theory to insist on its novelty. Chartists and professionals were not the only targets. Many financial economists used the publication of textbooks as an opportunity to express their dissatisfaction with the traditional approach. However, after the 1960s, once financial economics was permanently embedded in science, the debates disappeared: they lost their significance, because the scientific community and many financiers permanently recognized and adopted financial economics.

\subsection{The Links with Economics through \\ the Construction of Efficient Market Theory}

The new seminars and publications contributed to the creation of a truly homogenous community, which shared common problems, common tools, and a common language, as well as scientific journals and courses in universities. The use of the theory of modern probability, in particular the concept of uncertainty, offered new perspectives on already existing problems. At that time, however, such developments were technical and theoretical explanations did not exist. In other words, during this period the modern probability theory provided new tools that the social sciences could exploit, but, obviously, that was not enough to build a new discipline: a model does not contain causalities per se, because the choice 
between endogenous variables and exogenous variables comes from theoretical frameworks. Indeed, a theory gives causalities that allow one to define the structure of the model. These new tools from modern probability theory cannot provide an explanation of the empirical environment. Therefore, theoretical frameworks were necessary to introduce financial economics into science. More precisely, it was necessary to link the new approach with an existing science or with the criteria of conventional acceptance $^{12}$ of that time. The use of the contemporaneous scientific method-the tests and the hypothetico-deductive method-already constituted an important link. However, during the 1960s, the crucial step for the creation of financial economics was the construction of theoretical explanations based on concepts from economics.

The lack of theoretical explanations before the 1960s. Before the 1960s, there existed no theory explaining the new results in portfolio selection or in the random character of stock market prices. This crucial point illustrates what kept financial economics from becoming a scientific subdiscipline. The absence of theory characterizes all existing works written during that transitional period (see Jovanovic 2007).

Neither Cowles (1933), Working (1934), nor Kendall (1953), who were the first Anglo-Americans to analyze the random character of stock prices, created any theory to explain the phenomenon. Indeed, the enthusiasm for the new econometric practices developed since the 1930s clouded the research for theoretical explanations of the random character of stock prices. Theoreticians pointed out the absence of theoretical explanations during the 1950s. This was particularly striking after the KoopmansVining debate at the end the 1940s, which set the NBER against the Cowles Commission over the lack of theoretical explanations and the need to link measurement with theory. ${ }^{13}$ For instance, when Maurice Kendall published his statistical study on random price fluctuations in 1953, it was accepted with interest even as its economic contribution was harshly criticized. The most important critique was the absence of links with economic theories or concepts (Houthakker 1953, 32; Prais 1953, 29)..$^{14}$

12. I consider that the acceptance of a theory or a theoretical model does not only depend on empirical validation; there is also the criterion of conventional acceptance. Conventional acceptance concerns the conventions-postulates, beliefs, etc. - that a theory (or a model) must respect in order to be accepted as a scientific result of a discipline.

13. The Koopmans-Vining debate deeply influenced the economics of the 1950s. On this controversy, see Mirowski 1989.

14. See also the remarks of Champernowne, Bartlett, Rao, and Jevons in the discussion that follows Kendall's article. 
These kind of debates among economists had a direct influence on the two main defenders of the random character of prices at that time, Working $(1956,1958,1961)$ and Roberts (1959), who also consistently highlighted the absence of theoretical explanations and the weakness of the statistical results. For instance, Roberts $(1959,9)$ pointed out that the independence of the variations - one of the two aspects of the random walk model with the distribution function-was still not established. Working $(1956,1436)$ underlined that there was no true verification of the random character of stock price variations and added that it was impossible to reject the chartist analysis with certainty. These remarks were very important because, at the end of the 1950s, there were very few authors who had published on the subject.

The random walk caught up with economics. Theoretical explanations finally came during the 1960s when empirical and mathematical results were linked with economic equilibrium. Although they recognized the absence of theoretical explanations for the random character of stock price fluctuations, Working and Roberts were also the first to make links with economic theories in order to give theoretical foundations to empirical observations. Roberts $(1959,7)$ used the "arbitrage proof" argument, which is an extension of the economic law of one price in perfect capital markets: the forces of competition will ensure that any given commodity will be sold at the same price. Franco Modigliani and Merton Miller, one of Roberts's colleagues in Chicago, popularized this argument in their article published in $1958 .{ }^{15}$ The argument forged a first link between economics and financial results: their demonstrations are an implication of equilibrium in a perfect capital market, which provides a direct link with economic equilibrium. Roberts used it for the same aim: to create a link between economic concepts and the random walk model. On the other hand, Working (1956) established an explicit link between the unpredictable arrival of information and the random character of stock price changes. Another important step was the identification of a link between financial econometric results and the equilibrium from economics made by Cowles (1960, 914-15). By making a first reference to a competitive market, this article constituted the beginning of a connection with the standard economic theory that progressively led to an elaboration of the efficient market

15. Although Modigliani and Miller were not the first to apply the arbitrage proof in finance (Rubinstein 2003), their article led to its popularity for two reasons: (1) their article was one of the first to use modern probability theory to analyze a financial problem; and (2) the authors were members of strong academic departments (MIT and the University of Chicago). 
theory. And, two years later, Cootner $(1962,25)$ presented the idea of the efficient market theory, although he did not use that expression. Indeed, he suggested linking the random walk model, information, and economic equilibrium.

Several of his students took up and promoted his suggestion. It also interested researchers at the University of Chicago Graduate School of Business, most notably a young graduate student, Eugene Fama. In his $\mathrm{PhD}$ thesis, defended in 1964 and published the next year in the Journal of Business, Fama synthesized empirical work and gave his first formulation of the efficient market theory. He formulated the definition of the efficient market that is generally used in his 1970 article: "a market in which prices always 'fully reflect' available information is called 'efficient" " $(1970,383)$. According to the efficient market theory, if the model of equilibrium does not use all available information to evaluate the value of a security, it will be possible to make an arbitrage. Thus, in an efficient market, the equalization between the price and the equilibrium value means that all available information is included in the price. Consequently, it is not possible to use past information to predict the future changes of the prices: present and future prices are independent from the past prices. ${ }^{16}$ For this reason, in an efficient market, stock price changes must be as random as the arrival of new information. In other words, according to this theory, the random walk model can simulate the dynamic evolution of equilibrium prices in a competitive market. As a result of this link with economic equilibrium, the efficient market hypothesis, as well as portfolio selection and arbitrage proof (Jovanovic 2007), allowed the introduction of financial economics into science.

\section{The Internal Organization of the New Discipline}

The first part of this essay examined the integration of financial economics into science. The second part will analyze the internal organizationthe positions and relationships in the subfield-of the new subdiscipline. We have seen that, during the 1960s, several theoretical links were made between the random walk model and economic concepts and theories. Although the links could give a theoretical explanation to the random character of stock prices, the explanation was not unique. This second part

16. This is a property of the random walk model, which is a Markov process. 
shows that two theoretical viewpoints coexisted: the first contended that financial markets are perfect markets and that stock prices follow a pure random walk, and the second that financial markets are not perfect and that stock prices do not follow a pure random walk. Roughly, the University of Chicago Graduate School of Business defended the first position, while MIT defended the second. These two viewpoints structured the new subfield. They also directly influenced empirical investigations conducted during the 1960s and led to the creation of two canonical histories of financial economics.

\subsection{The Defense of Two Theoretical Viewpoints}

Two theoretical viewpoints. As I explained above, Cootner (1962) was one of the first to sketch the efficient market theory. However, after his suggestion to link the random movements of stock prices with the idea of perfect stock markets, Cootner (1962, 25-26) added:

Where else can the economist find that ideal of his-the perfect market? Here is a place to take a stand, if there is such a place. Unfortunately, it is not the right place. The stock market is not a random walk. A growing number of investigators have begun to suspect it, and I think I have enough evidence to demonstrate the nature of the imperfections. On the other hand, I do not believe that the market is grossly imperfect. In fact, I do not know why the process I see going on in the market is not worthy of the name perfection too. It strays from "perfection" only to the extent that it defines the Frank Knight-Milton Friedman assumption of profitless speculation. Even more interesting, perhaps, is that my model is perfectly compatible with much of what I interpret Wall Street chart reading to be all about.

Cootner's position gives a clear illustration of the MIT position: stock markets are not perfect. Moreover, theoreticians at MIT defended Keynesian considerations, in particular the Keynesian "normal backwardation" of commodity prices, ${ }^{17}$ which is not completely relevant to the markets' perfection. In 1960, Cootner answered Lester Telser, a young scholar at the University of Chicago, about the possibility of a perfect stock market.

17. The normal backwardation is a fee paid by a seller of a security to the buyer for the privilege of deferring delivery. It implies that a risk premium exists so that futures prices fall short of the expected future spot price. 
Telser expressed Knightian doubts about Keynes's normal backwardation. Telser used the no-arbitrage opportunity to suggest that there would be no difference between the price of futures and the spot price expected upon expiration of that contract, and that futures would give an unbiased estimate of such expected prices (Cootner 1960, 397). In this case, stock markets would be perfect, a position Cootner criticized. ${ }^{18}$

The idea that stock markets are not perfect also influenced Cootner's conception of the random character of stock prices. He suggested that prices behave as a constrained random walk within "reflecting barriers." He assumed that "when prices neared the barrier there would be a tendency for some negative autocorrelation, since movements to the barrier would be more likely to be followed by movements in the opposite direction" $(1962,28)$. The following year, his constrained random-walk model was validated empirically by one of his students, William Steiger. Cootner's model was supported by Samuelson $(1982,114)$, who explained, "I believe Paul Cootner was right to doubt that the speculative price of a stock, bond, grain futures, grain physical, machine tool, or acre of perpetual land would wander endlessly (like $\sqrt{ } T$ ) away from its rendezvous with its equilibrium dictated by economic law. His reflecting barriers were a valiant attempt to evade the unacceptable."19 MIT's position on the imperfection of the stock markets was also shared by Working. Starting at the end of the 1950s, Working began to develop a theoretical explanation of the more or less random character of stock prices. He arranged shorttime movements of stock prices into two categories $(1956,1431)$. The first one includes movements related to pertinent new market information. This category is divided into three subcategories, according to whether the price movement was (1) exactly appropriate, in size and direction, to the new information that induced it; (2) larger than the new information warranted; or (3) smaller than the new information warranted. The second category is divided into two subcategories, according to whether the movement was (1) unrelated to any pertinent economic information; or (2) corrective, tending to eliminate existing price maladjustment. In another article, Working $(1958,192)$ added:

18. Samuelson also justified the introduction of the martingale model with the normal backwardation: he criticized the most restrictive properties of the random walk model, which precisely cannot explain "the alleged Keynes-Hicks-Houthakker-Cootner pattern of 'normal backwardation,"” or "the Cootner pattern" (Samuelson 1965a, 41).

19. Note that the increase of prices according to $\sqrt{ } T$, where $T$ is time, is a consequence of the independence of the stochastic process. Samuelson $(1982,108-10)$ gives a mathematical interpretation of Cootner's model. 
[The "perfect market"] assumption would impair the usefulness of our model because it would eliminate the differences of opinion that are the source of much trading in a real market. To provide for differences of opinion, it is necessary only to specify that the traders are human rather than superhuman in their mental capacity.

Finally, for Working as well as for MIT, stock markets are imperfect.

These positions were vastly different from those defended at the University of Chicago Graduate School of Business. One of the starting points of the CRSP was the defense of the random walk model, and Fama was "the most energetic and prolific randomist" (Lorie 1965, 17). As we saw above, they claimed that stock markets are perfect, and characterized them as efficient. To demonstrate this, they considered that financial markets are perfect and that they reflect the competitive market of economics with rational agents. Fama gave the first theoretical demonstration in his thesis. He considers two kinds of agents: on one hand, "sophisticated traders," who are the only fundamentalists and chartists able to determine the intrinsic value of securities; on the other hand, other participants who do not have this skill and who are responsible for the "noise" in stock markets. "Thus these two types of sophisticated traders [fundamentalists and chartists] can be roughly thought of as superior intrinsic-value analysts and superior chart readers. We further assume that, although there are sometimes discrepancies between actual prices and intrinsic values, sophisticated traders in general feel that actual prices usually tend to move toward intrinsic values" (1965a, 37-38). "Sophisticated traders," due to their skills, make a better evaluation of the intrinsic values than other agents do. The major feature here is the existence of a homogeneous group that shares the same intrinsic values - this group can be for instance institutional funds. To have an equalization between intrinsic values and prices, Fama adds another hypothesis: it is necessary that the financial resources of the "sophisticated traders" be superior to those of other agents (40). Because the "sophisticated traders" have the majority of financial resources and share the same intrinsic values, their actions lead to prices equaling the intrinsic values they share as well as to any consistent profit being erased. Therefore, according to Fama, no bubbles can arise, because "sophisticated traders" "may cause the 'bubbles' to burst before they have a chance to really get under way" (38). In the same way, these traders should guarantee independence in the arrival of new information (39). Finally, "the stock market may conform to the independence assumption of the random walk model even though the processes 
generating noise and new information are themselves dependant" (39). ${ }^{20}$ Therefore, no trader can make a profit.

The intensification of research in financial econometrics. Beginning in the $1960 \mathrm{~s}$, researchers began using computers, ${ }^{21}$ which increased the number of investigations using empirical data. However, contrary to what the traditional history generally presents, empirical results obtained during this period were not homogeneous: empirical investigations on stock price variations completely depended on the two theoretical viewpoints identified above.

At MIT, economists aimed to identify correlations in price series or to anticipate price variations. They first found support for their conviction that stock markets are not perfect in the initial research on the random character of stock price movements. The presence of trends and correlations in stock price movements had been noted by Cowles, who identified a bias that made it possible to predict fluctuations in the stock price of futures. Following a remark made by Working (1960) 22 about these "pretended trends," Cowles took once again to the calculus of his 1960 article: he obtained the same results (Cowles 1960, 914). Kendall also found significant correlations, but he minimized them. Alexander $(1961,9)$ wrote of Kendall's conclusion that

Kendall felt impelled to draw the moral that it is dangerous to generalize even from fairly extensive sets of data. For, from the behavior of wheat prices and the stock prices, one might have concluded that speculative markets do not generate autocorrelated price changes. . . . Alas, Kendall drew the wrong moral. The appropriate one is that if you find a single exception, look for an error.

Working from these first results, MIT's economists also identified systematic movements in price variations. Houthakker $(1961,166)$ analyzed stop orders and showed that "price changes are not purely random but follow certain longer run trends." Those trends could be exploited to make profits. ${ }^{23}$

20. Fama dropped his distinction between sophisticated traders and other traders in his 1970 article.

21. The first computers were created in the 1930 s, but did not become common in academic research laboratories until the 1960s; see Metropolis, Howlett, and Rota 1980.

22. Cowles and Jones (1937) obtained statistical correlations for monthly or weekly averages of daily stock prices. Working (1960) explains that the use of averages can introduce correlations not present in the original series.

23 . Houthakker $(1961,168)$ also showed that the normal law is not verified because the distribution of the time-series is much more leptokurtic. 
In his 1957 article, he had already shown that "large speculators show definite evidence of forecasting skill, both in the long and in the short run" (151). In addition, Alexander (1961) reexamined the main results that validate the random walk model. He concluded that trends exist. In 1962 , Cootner published an extensive study of weekly data on forty-five stocks. Essentially, he reported that prices appeared to move randomly when studied at one-week intervals. Nevertheless, he also found evidence of trends in the same data at fourteen-week intervals. ${ }^{24}$

At Chicago, economists worked toward a different goal. The CRSP wanted to validate the random walk model at any price. It was "the idée fixe of the school" (Niederhoffer 1997, 271). As Niederhoffer $(1997,270)$ explains, they were

a team of four of the most respected graduate students in finance [who] had joined forces with two professors, now considered venerable enough to have won or to have been considered for a Nobel prize, but at that time feisty as Hades and insecure as a kid on his first date. This elite group was studying the possible impact of volume on stock price movements, a subject I had researched. . . . I could see this Group of Six gathered together on a stairway landing, examining some computer output. Their voices wafted up to me, echoing off the stone walls of the building. One of the students was pointing to some output while querying the professors, "Well, what if we really do find something? We'll be up the creek. It won't be consistent with the random walk model." The younger professor replied, "Don't worry, we'll cross that bridge in the unlikely event we come to it."

This group tested the random character of stock market prices by different ways. Moore (1962) was one of the first to examine the serial correlation between successive price variations. His results suggested that previous price changes could not be used to predict future changes. Fama (1965a) studied the daily proportionate price changes of the thirty industrial stocks in the Dow Jones. He used several tests and his results supported the random walk hypothesis. In addition to these tests, members of the CRSP systematically tried to provide countertests against results that identified significant price correlations. For instance, following Alexander's 1961 results, Fama and Blume (1966) demonstrated that filter schemes cannot, in general, provide returns larger than a naive policy of buying and holding stocks.

24. Weintraub (1963), Mellon (1964), and Niederhoffer (1965) obtained similar results. 
Finally, the community in financial economics organized itself into two groups according to two theoretical viewpoints. Each group found empirical results to validate their theoretical positions. I will now analyze how each group elaborated its own canonical history.

\subsection{The Two Canonical Histories of Financial Economics}

The inauguration of financial economics as a science and the organization of research in the subdiscipline were accomplished through a particular manner of presenting the history of the discipline. This manner of presentation comes from the construction of the canon of theoretical articles, and it is due to the fact that the creation of the canon led to select references and particular founding fathers. The canon not only exaggerates the importance of a few great men or contributions but simultaneously excludes or discredits the noncanonical. It can also link the selected contributions with a particular historical presentation and perspective. During the 1960s, the creation of a canon of theoretical contributions became the basis of a canonical history. I will show, however, that during this decade there was not one canonical history of financial economics but two: each theoretical approach-perfect markets versus imperfect markets-created its own unique version to support a particular theoretical viewpoint.

I must, however, confess that the terminology is not completely satisfactory. The question is, Did the work of those theoreticians constitute genuine history? It is important to clarify that. During the 1960s, when canons were elaborated in financial economics, the creation of the canonical history of the subdiscipline was not a goal, but a consequence of the way that the canons were made. Therefore, judging their efforts according to the method used, the history they created was a history in name only. As I explained in the introduction, such "canonical histories" create merely an impression of historical analysis: they simply order theoretical contributions chronologically and then link them retrospectively, with perfect hindsight. Consequently, such links are neither historical assumptions nor historical results; they are invented stories of the past. For these reasons, I chose to call this presentation of the past a "canonical history."

The selection among references. The growing popularity of modern probability theory and the stochastic processes led Anglo-American economists to discover Bachelier's work on stock prices. A mathematician, Leon- 
ard Jimmie Savage, ${ }^{25}$ who worked at the University of Chicago, began reading Bachelier's work at the end of the 1950s, and, "around 1960, Haloid (now Xerox) machines in universities across the United States were busy running off copies of Bachelier's 60-year-old dissertation" (Hagin and Mader 1973, 61). This discovery led to the acknowledgment of a common founding father for financial economics. However, Bachelier was the only reference shared by the two main groups of researchers; indeed, the defense of different theoretical viewpoints led each group to select among references.

It can be observed that Cootner (1964) gave priority to MIT's thesis. However, Cootner's book contained articles that were published at a time when few authors dealt with the subject. Therefore, the articles contain only a few references, and some none at all. But whereas the paucity of references in Cootner may be defensible, the same cannot be said about the publications by the Chicago economists. When we compare Fama's articles and the book edited by Cootner, we note that Fama did not mention several references, in particular any thesis defended at MIT. More significantly, Fama's 1970 article does not mention any other references published after Cootner's book: apart from some articles reprinted in Cootner, he only referenced articles published by his colleagues at the University of Chicago. For instance, there is no mention of works developed at the University of California (e.g., Kassouf 1968), or of the 1968 special issue of the Journal of Financial and Quantitative Analysis on the random walk model. The same tendency can be found in Lorie and Hamilton 1973. In a similar fashion, Lorie and Brealey (1972, viii) explained in their preface:

We felt a need for a book of readings that included the most important articles in the development of the modern theory of portfolio management. After selecting the thirty-seven articles in this book, we were surprised to find that almost half of them were in some way associated with the Center for Research in Security Prices. ${ }^{26}$

25. He discovered Bachelier's book, Le jeu, la chance, et le hasard, around 1957. It is interesting to note that in libraries the book is shelved with the mathematics books. Moreover, as Osborne (1959b, 808) explained, Bachelier's thesis was "rather inaccessible (it is available in the Library of Congress rare book room)."

26. Let me be clear that, for the authors, the "modern theory of portfolio management" concerned the whole literature in financial economics of that time. Therefore, their book contained three parts: "The Behaviour of the Market" (with a section on market efficiency), "Portfolio Management," and the "Valuation of Securities." 
More precisely, while the references from works completed at the University of Chicago were exhaustive, very few works from elsewhere were cited.

Moreover, to stay in harmony with their theoretical viewpoints, Fama, Lorie, and Hamilton voluntarily ignored results and articles that did not accept the idea of a perfect market - the random walk model and market efficiency. For instance, in his article, Fama did not quote several results developed at MIT; neither the articles of Theil and Leenders (1965), Niederhoffer (1965), and Shelton (1967), nor the patterns identified by Cowles (1944) and Cowles and Jones (1937), were considered. LeRoy (1989, 1595) also explained that

Fama's interpretation of Victor Niederhoffer and M. F. M. Osborne's evidence on runs-successive price changes of the same signs-is difficult to square with the fair game interpretation. Niederhoffer and Osborne found that reversals-pairs of successive price changes of opposite sign-occurred two to three times as frequently as continuations. Such systematic patterns are inconsistent with the fair game model. Despite this, Fama concluded and emphasized that such patterns, even though statistically significant, do no imply market inefficiency.

To be precise, economists at the University of Chicago cited articles that contradicted the random character of stock price movements only when those articles obtained opposite results with the same kind of tests. In the same way, Fama, Lorie, and Hamilton did not mention the attempts of Working and Cootner to give theoretical foundations to the random walk model.

The choice to ignore works that did not share the same theoretical viewpoint had a crucial influence on the construction of the canonical history of financial economics.

The canonical history provided by MIT's theoretical viewpoint. Cootner's book, The Random Character of Stock Market Prices, was not only the first anthology of articles that analyzed random stock price movements; it was also the first to provide historical data of financial economics. Cootner organized the data according to the theoretical position defended at MIT: the imperfection of the stock exchange. His presentation consisted of justifying the search for correlations or predictability of stock price movements. It suggested a history in three steps: "origins and justification of the random walk theory," "refinement and empirical testing," and "the random walk hypothesis reexamined." 
For each step, Cootner discusses the place of the papers included, and their significance, in the historical development of the subject. He writes:

It is clear, however, that until fairly recently, the study of [speculative] prices was the province of the speculator, rather than the academician. To be sure, Louis Bachelier pioneered in this study over 60 years ago, but his work, about which we will soon learn more, stands as an isolated event. $(1964,1)$

While Roberts' paper gives, at some length, a justification of the assumption that stock prices should have independent increments, Bachelier had, some 59 years earlier, developed an elaborate mathematical theory of speculative prices based on that proposition and tested it. . . So outstanding is his work that we can say that the study of speculative prices has its moment of glory at its moment of conception. . . . It also marked the beginning of the theory of stochastic processes, a beginning which went unrecognized for decades. $(1964,3)$

If Bachelier was before his time in the development of probability he was even farther ahead in the analysis of stock market prices. It was not until 1934 that $\mathrm{H}$. Working revived the idea of random walk in commodity prices, and it was more than twenty years later before Kruizenga (1956), stimulated by some work of Samuelson, used methods similar to Bachelier's to evaluate put and call options. $(1964,5)$

After Cowles' work in the 1930's, there was little or nothing published along these lines until Kendall's 1953 paper. . . . The publication in 1959 of both Roberts and Osborne papers marked the beginning of the sharp recent increase in interest in this subject, by bringing it to the attention of the American academic audience for the first time since Cowles' articles in the thirties. (1964, 81-82)

According to Cootner, the history of financial economics starts in 1900 with Louis Bachelier. He is credited with having suggested for the first time the modeling of stock prices by a random walk. Then, Working, Cowles, and Kendall tested the random walk hypothesis between 1933 and 1956. However, it was the articles of Roberts and Osborne published in 1959 that really stimulated interest in these problems. The first statistical study was Moore's, in 1962. Cootner summarized in this way the two first steps of the history of financial economics. The following step, which occurred during the 1960s, was the reexamination of the random walk hypothesis. Cootner used several articles to point out three kinds 
of problems, the normal distribution, the independence of stock prices, and the stationary character of the process:

Most of the work that follows the Moore paper stresses, in one way or another, the deviation of stock prices from the Einstein-Wiener process. The Alexander-Larson-Cootner-Steiger papers all question the independence hypotheses. The Fama-Mandelbrot material questions the assumption of Gaussian increments. The Osborne paper examines the stationarity of the process. In raising these questions it was necessary to invent subtle new tests, or to apply more esoteric probability distribution theory. (Cootner 1964, 189)

This presentation in three steps justified the works developed at MIT, which aim to identify correlations in security prices: the random walk model had been a roughly formed first hypothesis that had to be improved.

Cootner's introductions also gave the first historical elements of the presentation of the past as well as the first canonical history. The elements of these introductions are reprinted in many other books and articles and had a great influence during the 1960s. Their influence can be seen in the reviews of Cootner's book that were published in the most important American journals between 1965 and 1968. ${ }^{27}$ The reviews used Cootner's introductions extensively and, therefore, helped circulate the historical data that became popular.

The canonical history provided by the Chicago viewpoint. Economists at the University of Chicago Graduate School of Business used historical data from Cootner's book, but they elaborated another canonical history, which is mainly found in Fama 1965a, Fama 1970, and Lorie and Hamilton 1973. The goal of this canonical history was to defend the random walk model. More precisely, it was constructed to impress upon readers the triumph of the model. Therefore, it described a linear history that focused on tests. Fama's articles provide a good illustration. Fama wants to build a testable theory although his definition of efficient market "has no empirically testable implications" $(1970,384)$.

Therefore, in his three articles (1965a, 1965b, 1970), Fama kept the same structure: the first part deals with theoretical implications of the random walk model and its links with the efficient market hypothesis, while the second part presents empirical results that validate the random

27. For instance, see Granger 1965, King 1965, Markowitz 1965, Weiss 1966, Beals 1966, and Rosett 1968. 
walk model. This sequence-theory then empirical results-is nowadays very familiar. It constitutes the hypothetico-deductive method, the scientific method defended in economics since the middle of the twentieth century. Then, Fama linked the historical data with a methodological perspective: he used the historical data that he did not discard to suggest that the efficient market hypothesis would be successfully validated. Thus, the canonical history that arises from Fama gave the following presentation: the origin of the random walk model/efficient theory; the first generation of empirical tests; then, the second generation of empirical tests that also constituted a future program of research.

In his thesis, Fama (1965a, 41) gave a short presentation of the history of the random walk model in financial economics:

The first complete development of a theory of random walks in security prices is due to Bachelier, whose original work first appeared around the turn of the century. Unfortunately his work did not receive much attention from economists, and in fact his model was independently derived by Osborne over fifty years later. The Bachelier-Osborne model begins by assuming that price changes from transaction to transaction in an individual security are independent, identically distributed random variables.

This would be the origin of the random walk model, which Fama called the Bachelier-Osborne model. Then, Fama pointed out that the first tests were not satisfactory:

Although Osborne attempted to give an empirical justification for his theory, most of his data were cross-sectional and could not provide an adequate test. Moore and Kendall, however, have provided empirical evidence in support of the Gaussian hypothesis. (42)

In his 1970 article, he added:

Kendall's conclusion had in fact been suggested earlier by Working [1934], though his suggestion lacked the force provided by Kendall's empirical results. (390)

In 1970, Fama introduced three forms of efficiency: the weak form, the semi-strong form, and the strong form. Following this presentation, Fama, Lorie, and Hamilton classified works according to the form of efficiency they tested. However, they only dealt with results that validated the random walk model. 
We can notice that this presentation seems close to Cootner's book, which was the main source used by Fama. However, there are two important differences in Cootner: on one hand, the place given to efficiency and, on the other hand, that given to the tests. The methodological perspective adopted in Fama's history suggested a linear history that strengthens the idea of the random character of the triumph of stock prices: each time a result invalidated that hypothesis, authors from Chicago provided a counterexample against the result. This methodological perspective created continuities between authors or empirical investigations but the continuities were ad-hoc constructions and they were not compatible with historical data. For instance, the term "Bachelier-Osborne model" suggested a continuity that did not exist because Osborne did not know Bachelier's work when he published his article. We have exactly the same thing with the empirical tests and investigations presented in the first part.

\section{Concluding Comments}

A final observation must be made. If we analyze ideas defended in textbooks and scientific journals, we must admit that since the 1970s, it is the efficient market theory that has been most widely disseminated, and can be considered as having won the theoretical battle: witness the assimilationalthough theoretically contestable; see Jovanovic 2003a-of the random walk model and market efficiency. It is not the goal of the present article to explain either the reasons for this victory or its theoretical consequences. However, with the triumph of the efficient market theory, the canonical history of the University of Chicago Graduate School of Business has been widely spread in scientific journals and in textbooks. It has been presented or extended by Bernstein (1992), Walter (1996, 2002), Merton (1998), Scholes (1998), Dimson and Mussavian (1999, 2000), and Whelan, Bowie, and Hibbert (2002), among others. It is, however, important to recall two points.

First, a large majority of contemporary tests validate the random character of stock price movements or returns. ${ }^{28}$ But what was the situation during the 1960s and before? Houthakker and Williamson (1996) tested the random character of stock prices during three periods: January 1969

28. It must be kept in mind that the random character of stock prices does not automatically validate the efficient market theory.

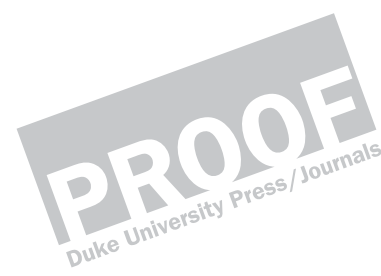


to June 1975; July 1975 to June 1982; and July 1982 to June $1992 .{ }^{29}$ They showed that "the stock market, as measured by the S\&P 500, did not follow a random walk during the first two periods but did so in the third period. In other words, the market became more efficient over the years" (136). They added, "It is somewhat ironic that in the 1970s, when the EMH [efficient market hypothesis] gained widespread acceptance, there were significant departures from a random walk. Fortunately for financial theory-and for the functioning of our capital markets-the market now conforms closely to a random walk. Reality has caught up with theory" (136). Therefore, empirical tests were not the main element that led to the adoption of the efficient market theory and the random character of stock market prices. This observation has an important implication: during the 1960s, MIT economists gave a better description of these movements; however, the history they defended was not the one retained.

Second, considering the number of publications and the content of textbooks, we note that the efficient market theory triumphed. This triumph, and with it the wide acceptance of the canonical history defended by the CRSP, has left forgotten many authors and contributions that do not enter into the framework of that history - for instance, Jules Regnault and Irving Fisher. ${ }^{30}$ The canonical histories analyzed here also obscured the fact that Anglo-American mathematicians had known Bachelier's mathematical works since the 1910s, although they did not use them often. ${ }^{31}$ The Calcul des probabilités, published in 1912, gave to Bachelier international recognition in the mathematics community, and some Anglo-American mathematicians used Bachelier to answer financial problems. ${ }^{32}$

29. The three periods coincided with fundamental changes in transaction costs, which can prevent informed investors from fully using their information: in 1975, fixed commissions were abolished; and in 1982, stock index futures were introduced, which was tantamount to a further reduction in transaction costs. However, as Houthakker and Williamson $(1996,136)$ clarified, while these changes in transaction costs were consistent with the evolution of efficiency, this link does not prove that markets became more and more efficient because transaction costs were reduced.

30. On Fisher's financial work, see Dimand 2004.

31. We can note that Samuelson had known of Bachelier's work at the end of the 1930s (Taqqu 2001, 26). However, before the Second World War, no American school of mathematics existed. Therefore, although Bachelier's work was known by some American mathematicians, it was not disseminated systematically. On the dissemination of Bachelier's work, see Jovanovic 2004 and Taqqu 2001.

32. For instance, in December 1922 at the meetings of the Mathematical Association of America, Arne Fisher used Bachelier's formulas to resolve financial problems (Cairns 1923, 97).

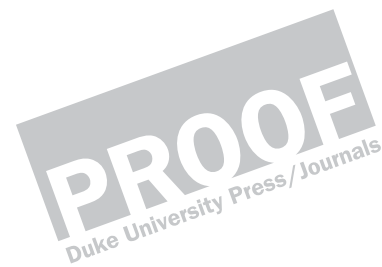


Beyond these theoretical and historical questions, this article has shown that financial economics became a scientific discipline during the $1960 \mathrm{~s}$ thanks to the creation of a new community of researchers and to the linking of empirical and mathematical anterior results with economic concepts and theories. However, the fight between two theoretical viewpoints marked the integration of financial economics into science. This article has demonstrated that to defend their theoretical viewpoints, each group created its own representation of the past of their discipline, that is, their own canonical history. The representations of the past of the discipline were weapons in the theoretical fights.

\section{References}

Alexander, Sidney S. 1961. Price Movements in Speculative Markets: Trends or Random Walk. Industrial Management Review 2:7-26.

Archer, Stephen H. 1968. Introduction. Journal of Financial and Quantitative Analysis 3.3:231-33.

Beals, Ralph E. 1966. The Random Character of Stock Market Prices: A Book Review. Journal of Political Economy 74.2:219.

Bernstein, Peter L. 1992. Capital Ideas: The Improbable Origins of Modern Wall Street. New York: Free Press.

Bourdieu, Pierre. 1975. La spécificité du champ scientifique et les conditions sociales du progrès de la raison. Sociologie et sociétés 7.1:91-118.

- 2004. Science of Science and Reflexivity. Cambridge: Polity.

Cairns, W. D. 1923. Seventh Annual Meeting of the Mathematical Association of America. American Mathematical Monthly 30.3:87-104.

Chaumont, Loïc, Laurent Mazliak, and Marc Yor. 2004. Quelques aspects de l'œuvre probabiliste. In L'héritage de Kolmogorov en mathématiques, edited by Eric Charpentier, Annick Lesne, and Nicolaï Nikolski. Paris: Belin.

Cootner, Paul H. 1960. Returns to Speculators: Telser versus Keynes. Journal of Political Economy 68.4:396-404.

1962. Stock Prices: Random vs. Systematic Changes. Industrial Management Review 3.2:24-45.

— ed. 1964. The Random Character of Stock Market Prices. Cambridge: M.I.T. Press.

Cowles, Alfred. 1933. Can Stock Market Forecasters Forecast? Econometrica 1.3:309-24.

- 1944. Stock Market Forecasting. Econometrica 12.3-4:206-14.

- 1960. A Revision of Previous Conclusions regarding Stock Price Behavior. Econometrica 28.4: 909-15.

Cowles, Alfred, and Herbert E. Jones. 1937. Some A Posteriori Probabilities in Stock Market Action. Econometrica 5.3:280-94. 
Dimand, Robert W. 2004. Irving Fisher and the Origins of Modern Finance: The Equity Premium Puzzle, the Predictability of Stock Prices, and Intertemporal Allocation under Risk. Paper presented at the History of Economics Society meetings, Victoria University in the University of Toronto, June.

Dimson, Elroy, and Massoud Mussavian. 1999. Three Centuries of Asset Pricing. Journal of Banking \& Finance 23.12:1745-69.

- 2000. Market Efficiency. In vol. 3 of The Current State of Business Disciplines, edited by Bhagwan Shri Dahiya, 959-70. Rohtak, India: Spellbound.

Fama, Eugene F. 1965a. The Behavior of Stock-Market Prices. Journal of Business 38.1:34-105.

-1965b. Random Walks in Stock-Market Prices. Financial Analysts Journal 21.5:55-59.

- 1970. Efficient Capital Markets: A Review of Theory and Empirical Work. Journal of Finance 25.2:383-417.

Fama, Eugene F., and Marshall E. Blume. 1966. Filter Rules and Stock-Market Trading. Journal of Business 39.1, pt. 2: Supplement on Security Prices, 226-41.

Fama, Eugene F., and Merton H. Miller. 1972. The Theory of Finance. New York: Holt.

Fredrikson, E. Bruce. 1965. Frontiers of Investment Analysis. Scranton, Penn.: International Textbook Co.

- 1971. Frontiers of Investment Analysis. Scranton, Penn.: Intext Educational Publishers.

Granger, Clive W. J. 1965. The Random Character of Stock Market Prices: A Book Review. Journal of the Royal Statistical Society, ser. A, 128.3:447-49.

— 1970. What the Random Walk Model Does Not Say. Financial Analysts Journal 26.3:91-93.

Hagin, Robert, and Chris Mader. 1973. What Today's Investor Should Know about the New Science of Investing. Homewood, Ill.: Dow Jones-Irwin.

Hoffland, D. L. 1967. The Folklore of Wall Street. Financial Analysts Journal 23.3:85-88.

Houthakker, Hendrik S. 1953. Discussion on Professor Kendall's Paper, The Analysis of Economic Time-Series. Journal of the Royal Statistical Society 116.25-34.

1957. Can Speculators Forecast Prices? Review of Economic Statistics 39.2:143-51.

- 1961. Systematic and Random Elements in Short-Term Price Movements. American Economic Review 51.2:164-72.

Houthakker, Hendrik S., and Peter J. Williamson. 1996. The Economics of Financial Markets. New York: Oxford University Press.

Jean, William H. 1970. The Analytical Theory of Finance: A Study of the Investment Decision Process of the Individual and the Firm. New York: Holt, Rinehart.

Jensen, Michael C. 1967. Random Walks: Reality or Myth? Comment. Financial Analysts Journal 23.6:77-85.

Jovanovic, Franck. 2002. Le modèle de marche aléatoire dans la théorie financière quantitative. PhD diss., University of Paris 1, Panthéon-Sorbonne. 
2003a. Le modèle de marche aléatoire dans l'économie financière de 1863 à 1976. Working paper.

- 2003b. Why Does the History of Financial Quantitative Theory Have to Be Rebuilt? Working paper presented at the thirty-fourth annual meeting of the History of Economics Society.

- 2004. The Construction of Financial Economics: A Sociological and Historical Analysis. Working paper.

—. 2006. A Nineteenth-Century Random Walk: Jules Regnault and the Origins of Scientific Financial Economics. In Pioneers of Financial Economics, edited by Geoffrey Poitras, 191-222. Cheltenham: Edward Elgar.

- 2007. The CAPM, the Modigliani-Miller Theorems, and the Rise of Modern Finance. In 20th Century Pioneers of Financial Economics, edited by Geoffrey Poitras and Franck Jovanovic, 157-69. Cheltenham: Edward Elgar.

Jovanovic, Franck, and Philippe Le Gall. 2001. Does God Practice a Random Walk? The "Financial Physics" of a 19th Century Forerunner, Jules Regnault. European Journal of the History of Economic Thought 8.3:323-62.

Kassouf, Sheen T. 1968. Stock Price Random Walks: Some Supporting Evidence. Review of Economic Statistics 50.2:275-78.

Kendall, Maurice George. 1953. The Analysis of Economic Time-Series. Pt. 1: Prices. Journal of the Royal Statistical Society 116:11-25.

King, Benjamin. 1965. The Random Character of Stock Market Prices: A Book Review. Journal of Finance 20.3:547-48.

Kruizenga, Richard J. 1956. Put and Call Options: A Theoretical and Market Analysis. PhD diss., MIT.

LeRoy, Stephen F. 1989. Efficient Capital Markets and Martingales. Journal of Economic Literature 27.4:1583-1621.

Levy, Robert A. 1967. Random Walks: Reality or Myth? Financial Analysts Journal 23.6:69-77.

1968. Random Walks: Reality or Myth? Reply. Financial Analysts Journal 24.1:129-32.

Lorie, James Hirsch. 1965. Controversies on the Stock Market. Selected Papers no. 20, Graduate School of Business of the University of Chicago.

Lorie, James Hirsch, and Richard A. Brealey. 1972. Modern Developments in Investment Management: A Book of Readings. New York: Praeger.

Lorie, James Hirsch, and Mary T. Hamilton. 1973. The Stock Market: Theories and Evidence. Homewood, Ill.: Irwin.

Mandelbrot, Benoit. 1966. Forecasts of Future Prices, Unbiased Markets, and "Martingale" Models. Journal of Business 39.1, pt. 2: 242-55.

Mao, James C. T. 1969. Quantitative Analysis of Financial Decisions. [New York]: Macmillan.

Markowitz, Harry M. 1952. Portfolio Selection. Journal of Finance 7.1:77-91. 1959. Portfolio Selection: Efficient Diversification of Investments. New York: Wiley.

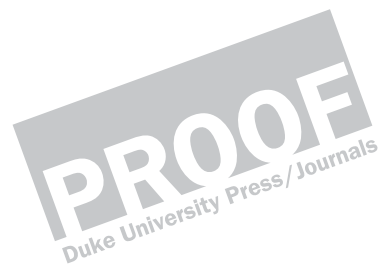


1965. The Random Character of Stock Market Prices: A Book Review. Journal of the American Statistical Association 60.309:381.

Mazliak, Laurent. 2003. Andrei Nikolaievitch Kolmogorov (1903-1987): Un aperçu de l'homme et de l'œuvre probabiliste. Working paper.

Mehrling, Perry. 2005. Fischer Black and the Revolutionary Idea of Finance. Hoboken: John Wiley \& Sons.

Mellon, W. Giles. 1964. On the Use of Time Series Analysis for Financial Prediction. Journal of Finance 19.2, pt. 1: 170-85.

Merton, Robert C. 1998. Applications of Option-Pricing Theory: Twenty-Five Years Later. American Economic Review 88.3:323-49.

Metropolis, N., J. Howlett, and G.-C. Rota, eds. 1980. A History of Computing in the Twentieth Century : A Collection of Essays. New York: Academic Press.

Mirowski, Philip. 1989. The Measurement without Theory Controversy. Oeconomia 11.65-87.

Moore, Arnold B. 1962. A Statistical Analysis of Common-Stock Prices. PhD diss., University of Chicago.

Moore, Basil J. 1968. An Introduction to the Theory of Finance: Assetholder Behavior under Uncertainty. New York: Free Press.

Niederhoffer, Victor. 1965. Clustering of Stock Prices. Operations Research 13.2:258-65.

1997. The Education of a Speculator. New York: John Wiley \& Sons.

Niederhoffer, Victor, and M. F. M. Osborne. 1966. Market Making and Reversal on the Stock Exchange. Journal of the American Statistical Association 61.316:897-916.

Osborne, M. F. M. 1959a. Brownian Motion in the Stock Market. Operations Research 7.2:145-73.

- 1959b. Reply to "Comments on 'Brownian Motion in the Stock Market.", Operations Research 7.6:807-11.

. 1962. Periodic Structure in the Brownian Motion of Stock Prices. Operations Research 10.3:345-79.

Prais, S. J. 1953. Discussion on Professor Kendall's Paper, The Analysis of Economic Time-Series. Pt. 1: Prices. Journal of the Royal Statistical Society 116.25-34.

Roberts, Harry V. 1959. Stock-Market "Patterns" and Financial Analysis: Methodological Suggestions. Journal of Finance 14.1:1-10.

Rosett, Richard N. 1968. The Random Character of Stock Market Prices: A Book Review. Econometrica 36.1:191-92.

Roy, A. D. 1952. Safety First and the Holding of Assets. Econometrica 20.3:431-49.

Rubinstein, Mark. 2003. Great Moments in Financial Economics: II. ModiglianiMiller Theorem. Journal of Investment Management 1.2:7-13

Samuelson, Paul A. 1965a. Proof That Properly Anticipated Prices Fluctuate Randomly. Industrial Management Review 6.2:41-49.

. 1965b. Rational Theory of Warrant Pricing. Industrial Management Review 6.2:13-40.

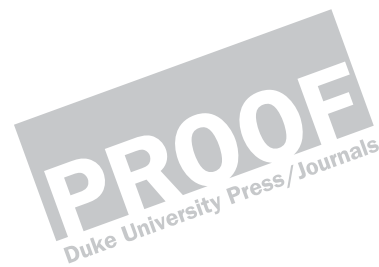


1982. Paul Cootner's Reconciliation of Economic Law with Chance. In Financial Economics: Essays in Honor of Paul Cootner, edited by William F. Sharpe and Cathryn M. Cootner. Englewood Cliffs, N.J.: Prentice-Hall.

Scholes, Myron S. 1998. Derivatives in a Dynamic Environment. American Economic Review 88.3:350-70.

Shelton, John P. 1967. The Value Line Contest: A Test of Predictability of StockPrice Changes. Journal of Business 40.3:251-69.

Steiger, William Lee. 1963. Non-randomness in the Stock Market: A New Test on an Existent Hypothesis. M.S. thesis, Massachusetts Institute of Technology School of Industrial Management.

Taqqu, Murad S. 2001. Bachelier and His Times: A Conversation with Bernard Bru. Finance and Stochastics 5.1:3-32.

Theil, Henri, and C. T. Leenders. 1965. Tomorrow on the Amsterdam Stock Exchange. Journal of Business 38.3:277-84.

Van Horne, J. C., and George G. C. Parker. 1968. Technical Trading Rules: A Comment. Financial Analysts Journal 24.4:128-32.

Wallich, H. C. 1968. What Does the Random Walk Hypothesis Mean to Security Analysts? Financial Analysts Journal 24.2:159-62.

Walter, Christian. 1996. Une histoire du concept d'efficience sur les marchés financiers. Annales HSS 51.4:873-905.

- 2002. From Bachelier's Dissertation to Portfolio Management Industry: One Aspect of the Bachelier Heritage in Finance. In Louis Bachelier, aux origines de la finance mathématique, edited by Jean-Michel Courtault and Youri Kabanov, 111-64. Besançon: Presses Universitaires de Franche Comté.

Weintraub, Robert E. 1963. On Speculative Prices and Random Walks[:] A Denial. Journal of Finance 18.1:59-66.

Weiss, Herbert K. 1966. The Random Character of Stock Market Prices: A Book Review. Operations Research 14.5:962-65.

Whelan, S. F., D. C. Bowie, and A. J. Hibbert. 2002. A Primer in Financial Economics. British Actuarial Journal 8.1:27-74.

Working, Holbrook. 1934. A Random-Difference Series for Use in the Analysis of Time Series. Journal of the American Statistical Association 29:11-24.

- 1956. New Ideas and Methods for Price Research. Journal of Farm Economics 38:1427-36.

- 1958. A Theory of Anticipatory Prices. American Economic Review 48.2:188-99.

1960. Note on the Correlation of First Differences of Averages in a RandomChain. Econometrica 28.4:916-18.

- 1961. New Concepts concerning Futures Markets and Prices. American Economic Review 51.2:160-63.

Wu, Hsiu-Kwang, and Alan J. Zakon. 1965. Elements of Investments. New York: Holt.

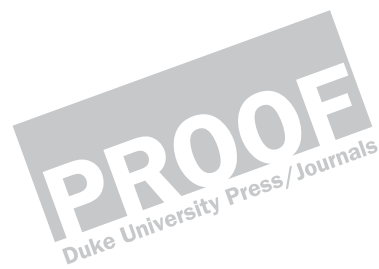

